\title{
Procalcitonin as early predictor of bacteremia in critically ill neutropenic patients
}

\author{
Karina Marín ${ }^{1}$, Luis Unigarro ${ }^{1 *}$, Emérita Basantes ${ }^{1}$, Henry Caballero ${ }^{1}$, Ana Gangotena², \\ Víctor Figueroa ${ }^{1}$ and Gustavo del Pozo ${ }^{3}$ \\ ${ }^{1}$ Intensive Therapy Department, Hospital Oncológico SOLCA; ${ }^{2}$ Critical Medicine and Intensive Therapy Postgraduate Program, Universidad Católica; \\ ${ }^{3}$ Department of Research, Universidad UTE. Quito, Ecuador
}

\begin{abstract}
Background: Procalcitonin (PCT) could predict the presence of bacteremia in critically ill patients with febrile neutropenia. The objective was to determine the predictive value of PCT in the diagnosis of bacteremia and its ability to differentiate between gram-negative and gram-positive organisms. Methods: Retrospective cohort study conducted at the Oncology Hospital "Solón Espinosa Ayala," Quito-Ecuador, which included patients who were admitted with febrile neutropenia to intensive therapy. PCT values were evaluated at admission together with blood culture samples, from 2010 to 2016 . Results: The association between PCT levels and the diagnosis of bacteremia was investigated in 117 patients. PCT demonstrated bacteremia discrimination with a point of cut of $15.5 \mathrm{ng} / \mathrm{ml}$ and an area under the curve (AUC) of 0.76. The concentration of PCT in patients with bacteremia by gram-negative germs was higher compared with patients with bacteremias by gram-positive germs, 26 vs. $7.1 \mathrm{ng} / \mathrm{ml}$ ( $p=0.001$ ). Values > $26.8 \mathrm{ng} / \mathrm{ml}$ predict bacteremia by Gram-negative bacilli (AUC: 0.81). Conclusions: $A$ cut-off value of $P C T>15.5 \mathrm{ng} / \mathrm{ml}$ is a predictor of bacteremia (AUC: 0.76 ) and values $>26.8 \mathrm{ng} / \mathrm{ml} \mathrm{predict}$ bacteremia by gram-negative bacilli (AUC: 0.81).
\end{abstract}

Key words: Procalcitonin. Bacteremia. Febrile neutropenia.

\section{Introduction}

Despite improvements in antimicrobial therapy and in the management of sepsis, infectious complications continue to be common in cancer patients with febrile neutropenia and entail worse prognoses.

A high index of suspicion is required with any infectious process, since late initiation of antibiotic therapy is associated with higher mortality ${ }^{1-3}$. The relative scarcity of infection-specific symptoms, in addition to delay in the delivery of culture results and the low probability of positivity in them, can lead to unnecessary delays or diagnostic and therapeutic errors in this type of patients ${ }^{4}$.
Procalcitonin (PCT), a calcitonin prohormone, is profusely produced in response to endotoxins and inflammation mediators in bacterial infections. It has become a widely used biomarker in the management of sepsis due to its low cost and high levels of sensitivity (Sens) and specificity (Sp) to predict systemic bacterial infections, as well as being indicative of the type of germ involved ${ }^{5-9}$. These characteristics make PCT an effective tool for infection early detection and guide for the start of appropriate empirical antibiotic therapy, with an important impact on survival ${ }^{10}$. The purpose of this study is to determine the diagnostic value of PCT in bacteremia early identification in critically ill febrile neutropenic patients.
Correspondence:

*Luis Unigarro

E-mail: luisunigarro3@gmail.com license (http://creativecommons.org/licenses/by-nc-nd/4.0/).

Date of reception: 10-08-2019

Date of acceptance: 27-09-2019

DOI: 10.24875/j.gamo.M19000194
Available online: 31-10-2019 Gac Mex Oncol. 2020;19(1):13-20 www.gamo-smeo.com 


\section{Materials and methods}

\section{Primary objective}

The purpose of this study is to determine the diagnostic value of PCT alone or in combination with other factors for early recognition of bacteremia in febrile neutropenic patients admitted to an intensive care unit, in addition to determining and suggesting cut-off points for the detection of gram-negative bacteria.

\section{Study design}

This was a retrospective cohort study, using the database of the oncological intensive care unit of the Solón Espinosa Ayala Hospital of the city of Quito.

\section{Study population and setting}

Inflammation markers such as PCT were determined as a line of study at the unit, and the data of patients admitted with suspected infection are therefore systematically documented and available for analysis in several subtopics previously programmed by the researchers, with the database operating uninterruptedly since 2010 .

\section{Participants}

All critically ill cancer patients admitted to the intensive care unit with febrile neutropenia and suspected infection from 2010 to 2016 were included. Patients had PCT values assessed upon admission to the unit along with blood culture samples, according to the usual care protocols of the unit,.

Solid and hematological neoplasms were included; patients who did not grant consent were excluded, as well as when obtaining samples for PCT or culture was not possible and patients with neuroendocrine tumors, since these neoplasms can erroneously elevate PCT values. Sepsis definitions are based on current guidelines ${ }^{3}$. Cultures that identified potentially contaminating germs were evaluated by a team of specialists.

\section{Ethical aspects}

The study did not include any type of special intervention, the patients signed an informed consent for comprehensive management upon admission, in adherence to which PCT and blood culture assessments were requested at the unit.
The study was approved by the hospital ethics committee (Committee of Ethics and Research on Human Beings) and the National Directorate of Health Intelligence of MSP-Ecuador (MSPCURI:000227-2). Data were handled with absolute adherence to standards of confidentiality and respect for the patient.

\section{Data collection and handling}

The samples were processed at hospital laboratories, which comply with institutional quality standards. The database is frequently subjected to quality assessment and its data are transferred for statistical analysis. The analyses were carried out with the R program.

\section{Statistical analysis}

The study was descriptive, with quantitative variables being reported as means \pm their standard deviation (mean $\pm \mathrm{SD}$ ); for those that did not meet normality criteria, the median was reported with its respective interquartile ranges $(R I Q)$ or with median absolute deviation (MAD). Categorical variables were reported with absolute and relative frequencies as percentages (\%). For the analysis of quantitative variables, Student's t-test was used for independent groups, after assessing for normality requirements, or with their non-parametric equivalents; when necessary, confidence intervals were obtained using resampling methods (boostrapping). The analyses used PCT values with logarithmic transformation (log), but significant values were reported in their original units whenever possible. For the analysis of more than two groups, one-way ANOVA was used. Post hoc tests were carried out with adjustment according to the Tukey method only in the presence of significant differences. For qualitative variables, independence was tested with the chi-square test (Pearson), with Fisher's exact test being used if necessary; stratum-wise adjustment used the Cochran-Mantel-Haenszel test and the multivariate methods described below.

Multivariate analyses were carried out using logistic regression methods, with the models being adjusted for significant variables and risk assessment being reported with its beta coefficients, in addition to its equivalents, such as adjusted odds ratios (adjOR) with their respective $95 \%$ confidence intervals (Cl). Predictive values were generated with internal validation, with cutoff points being reported with total performance, sensitivity and specificity values, in addition to generating receiver operating characteristic (ROC) curves. For all comparisons, values lower than $5 \%(p<0.05)$ were regarded as significant. 
Data were collected on a MS-Exce ${ }^{\circledR}$ spreadsheet designed for this purpose; statistical analysis was performed using the $\mathrm{R}$ program (version 3.5.3, 2019).

\section{Results}

During the study period, information on PCT levels of 117 patients with febrile neutropenia was collected and the results of their blood cultures were recorded.

\section{Demographic characteristics}

Of 117 patients included in the study, $49.6 \%$ were males and $50.4 \%$ were females. Average age was $52 \pm$ 18.5 years, with a range of 18 to 85 years. In general, hematological neoplasms predominated with $73.5 \%$, with the remaining $26.5 \%$ corresponding to solid tumors.

Previous corticosteroid therapy had been received by $64.1 \%$ of patients, whereas $66.7 \%$ received antibiotic therapy prior to admission to the unit. Acute Physiology And Chronic Health Evaluation II (APACHE II) median score was 21 points (IQR: 16.28 points) while the Sequential Organ Failure Assessment (SOFA) value was 8 points (IQR: 6.11 points).

Forty-five patients (38.5\%) had positive blood cultures. In the overall study population $(n=117), 31$ patients were positive for gram-negative bacteria (26.5\%), while 13 were positive for gram-positive microorganisms (11.1\%); 73 cultures (62.4\%) tested negative for bacterial development, and one patient was positive exclusively for fungi (with Candida albicans isolation). PCT showed wide variability, with values ranging from 0.07 to $794.8 \mathrm{ng} / \mathrm{mL}$, with a median value of $4.1 \mathrm{ng} / \mathrm{mL}$ (IQR: $0.56-17 \mathrm{ng} / \mathrm{mL}$ ).

Overall mortality in the intensive care unit was $29.1 \%$ ( $n=34$ ). Mortality at hospital discharge was $40.2 \%$ $(n=47)$. Mortality at the end of the 30-day follow-up was $53 \%(n=62)$.

\section{Baseline characteristics of the groups}

At the beginning of the follow-up, patients with positive and negative blood cultures showed similar characteristics with regard to gender, age and severity scales (APACHE II and SOFA). The type of neoplasm was also similar, with the hematological type predominating in both groups, with 72.2 vs. $75.6 \%$ for the groups with negative and positive blood cultures, respectively $(p=0.86)$.

Corticosteroid previous use was slightly higher in patients with positive blood cultures, while previous use
Table 1. Baseline, clinical and follow-up characteristics of the study sample

\begin{tabular}{|c|c|c|c|}
\hline Variable & $\begin{array}{l}\text { Negative } \\
\text { blood cultures } \\
\text { (n= 72) }\end{array}$ & $\begin{array}{l}\text { Positive blood } \\
\text { cultures } \\
\text { (n=45) }\end{array}$ & p-value \\
\hline $\begin{array}{l}\text { Age, years } \\
(\bar{x} \pm S D)\end{array}$ & $52 \pm 19$ & $52 \pm 18$ & 0.97 \\
\hline $\begin{array}{l}\text { Procalcitonin, } \\
\mathrm{ng} / \mathrm{mL} \\
(\overline{\mathrm{m}} \pm \mathrm{MAD})\end{array}$ & $1.8 \pm 2.5$ & $15.0 \pm 21.5$ & $<0.01$ \\
\hline $\begin{array}{l}\text { APACHE II, } \\
\text { points } \\
(\bar{m} \pm \text { MAD) }\end{array}$ & $21.0 \pm 8.0$ & $23.0 \pm 10.0$ & 0.64 \\
\hline $\begin{array}{l}\text { SOFA, points } \\
(\bar{m} \pm \text { MAD) }\end{array}$ & $8.0 \pm 4.0$ & $8.0 \pm 3.0$ & 0.64 \\
\hline $\begin{array}{l}\text { Type of } \\
\text { neoplasm, n (\%) }\end{array}$ & & & 0.86 \\
\hline Hematological & $52(72.2)$ & $34(75.6)$ & \\
\hline Solid & $20(27.8)$ & $11(24.4)$ & \\
\hline $\begin{array}{l}\text { Prior } \\
\text { corticosteroids, } \\
\text { n }(\%)\end{array}$ & $43(59.7)$ & $32(71.1)$ & 0.29 \\
\hline $\begin{array}{l}\text { Prior antibiotics, } \\
\text { n (\%) }\end{array}$ & $49(68.1)$ & $29(64.4)$ & 0.84 \\
\hline $\begin{array}{l}\text { ICU mortality, } \\
\mathrm{n}(\%)\end{array}$ & $15(20.8)$ & $19(42.2)$ & 0.02 \\
\hline $\begin{array}{l}\text { Hospital } \\
\text { mortality, n (\%) }\end{array}$ & $25(34.7)$ & $22(48.9)$ & 0.18 \\
\hline $\begin{array}{l}\text { 30-day mortality, } \\
\text { n }(\%)\end{array}$ & $33(45.8)$ & $29(64.4)$ & 0.08 \\
\hline
\end{tabular}

MAD: mean absolute deviation

of antibiotics was slightly higher in the group with negative blood cultures, although these small differences were not significant (Table 1).

In the course of follow-up, mortality differed between groups according to the development of germs in blood cultures. At intensive-care unit discharge, approximately $42.2 \%$ of patients with positive cultures had died ( $n=19 / 45$ ), in comparison with $20.8 \%$ of patients with negative blood cultures $(n=15 / 72)$; this meant an absolute risk difference of $21.4 \%$ (95\% Cl: $2.4-40.4 \%$; $p=0.02)$. The trend continued until 30 days of follow-up, although the differences did not reach significance in subsequent assessments (Table 1).

\section{Procalcitonin as a predictor of positive blood cultures}

Statistically significant differences in PCT values were found between the groups with and without positive 


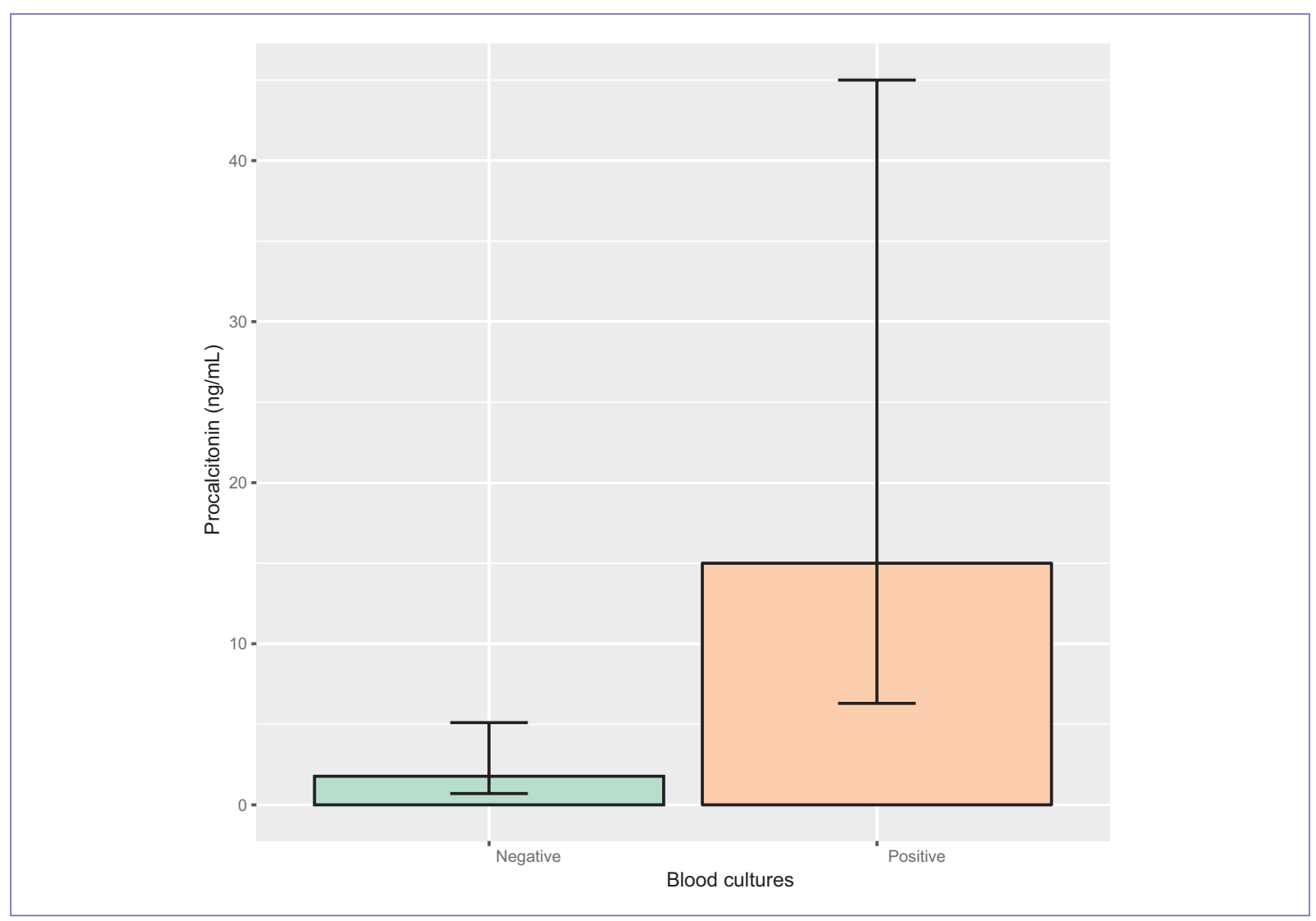

Figure 1. Procalcitonin mean values with their respective $95 \%$ confidence intervals in the groups with negative and positive blood cultures; median value is indicated; confidence intervals were estimated by bootstrapping.

blood cultures: for the group with negative blood cultures, average value was $1.8 \mathrm{ng} / \mathrm{mL}(M A D \pm 2.5 \mathrm{ng} / \mathrm{mL}$ ), while in the group with positive blood culture average value was $15 \mathrm{ng} / \mathrm{mL}$ (MAD $\pm 21.5 \mathrm{ng} / \mathrm{mL})(p<0.01)$; with the exception of these values, no differences were found in patient characteristics assessed at admission (Fig. 1 and Table 1).

Four fungal isolates (two albicans-type and two non-albicans) were reported, with only one being isolated independently, while the remaining three were concurrent with gram-negative bacteria isolates; this case had a PCT value of $18.9 \mathrm{ng} / \mathrm{mL}$.

Excluding the cases with multiple isolates, PCT mean level for patients infected with gram-negative bacteria was $43.9 \mathrm{ng} / \mathrm{mL}$ (MAD $\pm 47 \mathrm{ng} / \mathrm{mL})$, whereas for those with gram-positive bacteria it was $3.3 \mathrm{ng} / \mathrm{mL}$ $(M A D \pm 4.4 \mathrm{ng} / \mathrm{mL})$; those with negative cultures showed values of $1.8 \mathrm{ng} / \mathrm{ml}(M A D \pm 2.5 \mathrm{ng} / \mathrm{mL}$ ). Distribution by type of germ is presented in figure 2 and table 2.

In the multivariate analysis, only PCT showed a significant association with the development of germs in the culture (Table 3). With a cut-off point of $15.5 \mathrm{ng} / \mathrm{mL}$
Table 2. Procalcitonin values $(\mathrm{ng} / \mathrm{mL})$ associated with the types of isolates obtained

\begin{tabular}{|l|c|c|}
\hline Type of isolate & Median & IOR \\
\hline Gram-negative $(n=28)$ & 43.9 & $3.1-71.6$ \\
\hline Gram-positive $(n=13)$ & 3.3 & $1.0-12.0$ \\
\hline None $(n=72)$ & 1.8 & $0.3-9.3$ \\
\hline
\end{tabular}

Four patients with simultaneous isolates were excluded. IQR: interquartile range.

(Prob > 0.42), total performance was $69.4 \%$ (95\% Cl: $53.1-82 \%)$, with a sensitivity of $71.4 \%(95 \%$ Cl: $45.4-88.3 \%)$, specificity of $68.2 \%(95 \% \mathrm{Cl}: 47.3-$ $83.6 \%$ ), a positive predictive value (PPV) of $58.8 \%$ (95\% Cl: $36-78.4 \%)$ and a negative predictive value (NPV) of $78.9 \%(95 \% \mathrm{Cl}: 47.3-83.6 \%)$, with the ROC curve reaching an area under the curve (AUC) of 0.76 .

For the prediction of blood cultures with gram-negative development, PCT improved its performance in ROC total area under the curve (AUC: 0.8); as expected, higher values predicted the presence of this type 


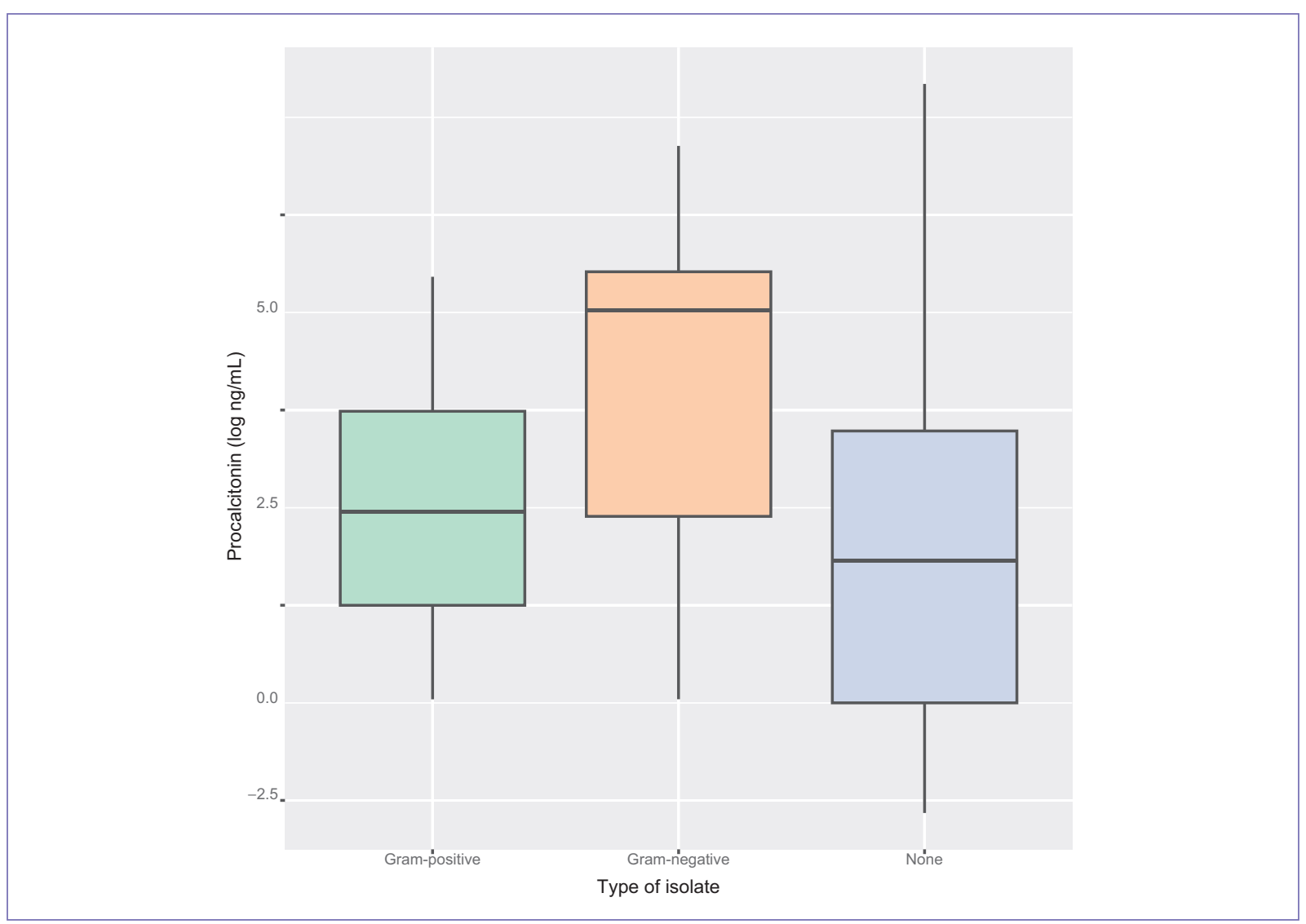

Figure 2. Procalcitonin values distribution according to the identified type of germ. Transformed values are indicated (log $\mathrm{ng} / \mathrm{mL})$.

Table 3. Factors associated with the development of positive cultures in the entire sample, with coefficients obtained by logistic regression*

\begin{tabular}{|c|c|c|c|c|}
\hline Variable & $\boldsymbol{\beta}$ & adjOR & $95 \%$ CI & p-value \\
\hline Procalcitonin $^{\dagger}$ & 0.46 & 1.58 & $1.21-2.13$ & 0.001 \\
\hline Age & 0.01 & 1.01 & $0.98-1.03$ & 0.6 \\
\hline Male gender & 0.41 & 1.51 & $0.52-4.56$ & 0.45 \\
\hline Solid tumor & -0.24 & 0.78 & $0.19-2.94$ & 0.72 \\
\hline SOFA & 0.01 & 1.01 & $0.87-1.17$ & 0.88 \\
\hline $\begin{array}{l}\text { Prior } \\
\text { corticosteroids }\end{array}$ & -0.1 & 0.91 & $0.28-2.87$ & 0.86 \\
\hline Prior antibiotics & 0.25 & 1.28 & $0.36-4.65$ & 0.7 \\
\hline
\end{tabular}

*Factors included for control, non-significant interaction effect, intercept (-1.82). ${ }^{\dagger}$ Model constructed with logPCT.

adjOR: adjusted odds ratio; SOFA: Sequential Organ Failure Assessment.

of germs with higher certainty, thus increasing specificity, but at the expense of sensitivity (see table 4 and figure 3 for cutoff points). Figure 3 shows a representation of the gram-negative curve.

\section{Discussion}

The present work, carried out in critically ill patients with febrile neutropenia, demonstrates the association between PCT levels and bacteremia diagnosis, both in the bivariate model and the logistic regression analysis, with a cutoff point of $15.5 \mathrm{ng} / \mathrm{mL}$ and a ROC area under the curve of 0.81 for the discrimination of gram-negative bacilli bacteremia, which is comparable to findings by the MEDUSA group ${ }^{11}$.

The best performance of the study is found in the prediction of gram-negative bacilli bacteremia, which have a higher microbiological prevalence in our institution (Fig. 4) ${ }^{12,13}$. The NPV for gram-positive germs has been reported at $98.4 \%$, with PCT levels between 0.4 and $0.75 \mathrm{ng} / \mathrm{mL}^{9,10}$. In the absence of bacterial infections, PCT level is rather low $(<0.1 \mathrm{ng} / \mathrm{mL})^{10}$; in the context of a febrile patient, low values should lead to investigate differential diagnoses that include viral infections and non-infectious fever causes ${ }^{14}$.

Several investigations provide evidence of an association between PCT high levels and bacteremia in 


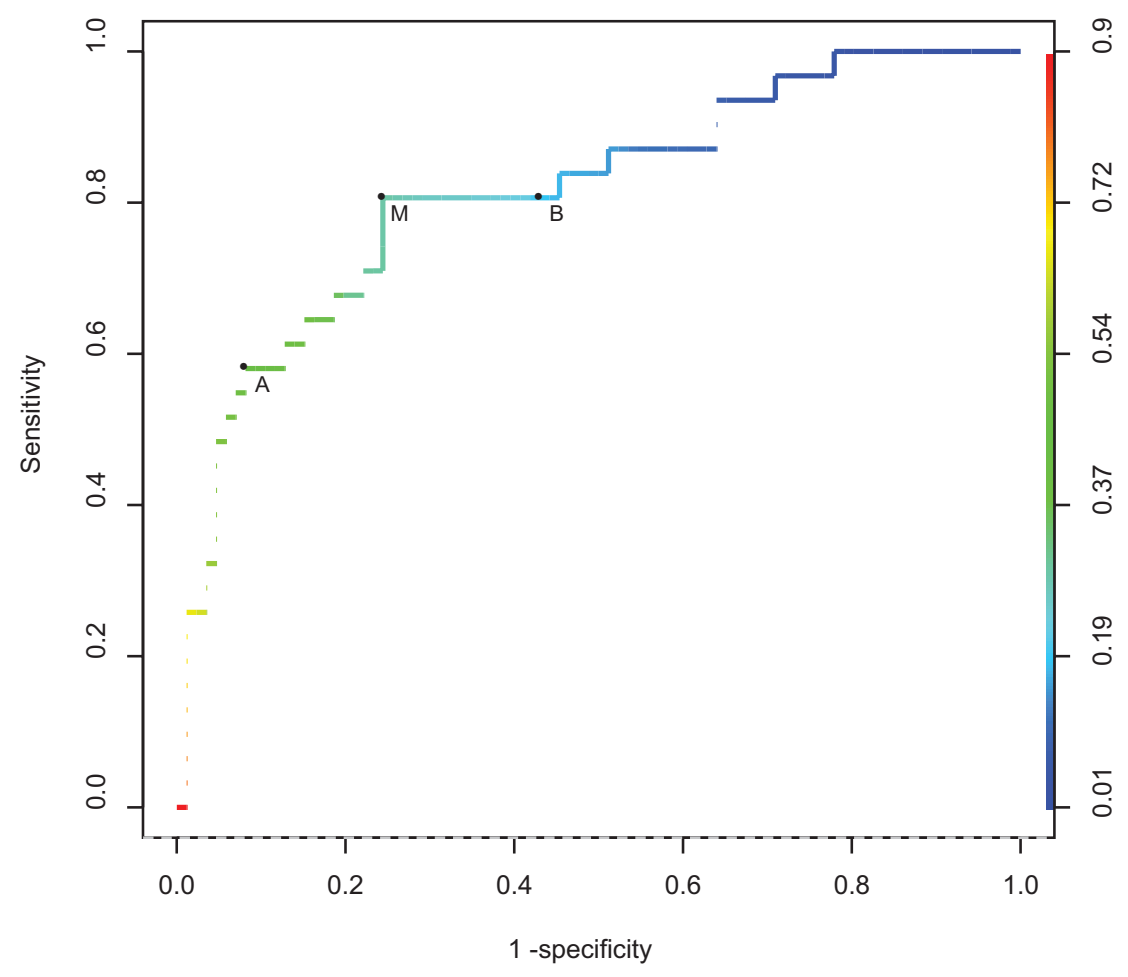

Figure 3. Procalcitonin performance for the prediction of positive blood cultures for gram-negative germs.

Table 4. Summary of procalcitonin performance in the prediction of bacteremia by any germ or exclusively by gram-negative germs

\begin{tabular}{|l|l|l|l|l|l|}
\hline $\begin{array}{l}\text { Procalcitonin cutoff } \\
\text { point }\end{array}$ & Sens & Sp & PPV & NPV & Per \\
\hline $\begin{array}{l}\text { Any germ* } \\
>15.5 \mathrm{ng} / \mathrm{mL}\end{array}$ & 71.4 & 68.2 & 58.8 & 78.9 & 69.4 \\
\hline $\begin{array}{l}\text { Gram-negative germs } \\
\text { High cutoff }\end{array}$ & 58.1 & 91.9 & 72.0 & 85.9 & 82.9 \\
\hline $\begin{array}{l}\text { (> 327.0 ng/mL) } \\
\text { Intermediate cutoff } \\
\text { (87.8 ng/mL) } \\
\text { Low cutoff } \\
\text { (> 26.8 ng/mL) }\end{array}$ & 80.6 & 75.6 & 54.3 & 91.5 & 76.9 \\
\hline
\end{tabular}

${ }^{*}$ Area under the curve (AUC) for any germ: 0.76 .

${ }^{\dagger}$ AUC for gram-negative germs: 0.81 .

Sens: sensitivity; Sp: specificity; PPV: positive predictive value; NPV: negative predictive value; Per: total performance (rate of correctly predicted positive and negative cultures).

patients with sepsis. Among the most recent and relevant is the MEDUSA multicenter trial, conducted in 4,858 patients with sepsis; the optimal cutoff point for bacteremia diagnosis was $10 \mathrm{ng} / \mathrm{mL}$, with an AUC of 0.72 , which is comparable to our results ${ }^{15,16}$.

In the MEDUSA trial ${ }^{11}$, PCT concentration in patients with gram-negative germ bacteremia was higher in comparison with that in patients with gram-positive germ bacteremia, at 26 vs. $7.1 \mathrm{ng} / \mathrm{mL}(\mathrm{p}=0.001)$. Patients with candidemia had a PCT level of $4.7 \mathrm{ng} / \mathrm{mL}$.

Another investigation determined PCT differences between bacteremia by enterobacteria and by non-fermenting gram-negative bacteria (17.1 vs. $3.5 \mathrm{ng} / \mathrm{dL} ; \mathrm{p}=0.0001)^{8}$.

PCT NPV for bacteremia has been reported as an important result ${ }^{14}$; for example, levels between 0.4 and $0.75 \mathrm{ng} / \mathrm{mL}$ have a NPV of $98.4 \%$ for gram-positive bacteria and $99.9 \%$ for anaerobes ${ }^{17}$.

In neutropenic immunocompromised patients, PCT sensitivity of $66 \%$ and specificity of $78 \%$ have been described for the diagnosis of bacteremia ${ }^{18}$. Our study has the advantage of providing data from a particularly vulnerable population. During febrile neutropenia, absence of a typical neutrophil-mediated inflammatory response is a known phenomenon, as, for example, in pneumonia without defined infiltrates and cellulitis without overt local inflammation, which makes it difficult for the infectious focus to be identified. PCT production is not affected by neutropenia during sepsis, since it is synthesized in the liver, the lung, the kidneys and the intestine, among other tissues ${ }^{19-22}$. 


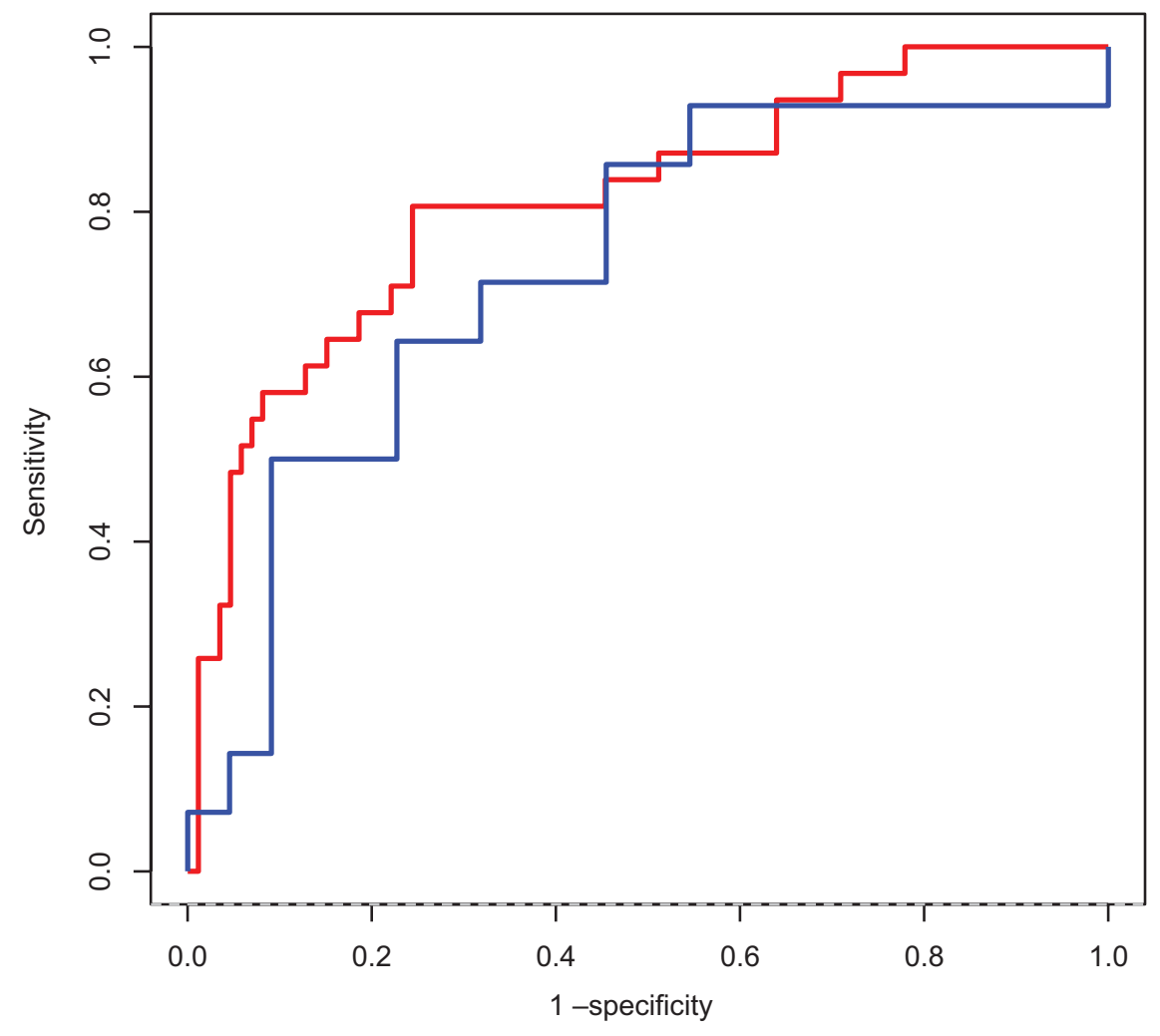

Figure 4. ROC curve for procalcitonin performance as a predictor of positive blood cultures (any germ, blue) and exclusively for gram-negative germs (red).

We found higher values in comparison with studies conducted in critically-ill non-neutropenic patients. The mechanism by means of which PCT is highly expressed by gram-negative bacteria could be explained by the stimulation of immune system Toll-like receptors (TLR4) by bacterial wall lipopolysaccharides, which activates the inflammation cascade, with the production of acute phase proteins such as C-reactive protein (CRP) and interleukins $1,6,8$ and $10^{7}$. PCT predictive capacity has been reported to be more specific than that of CRP (AUC: 0.71 vs. 0.49$)^{23-27}$.

Mortality in our patients was $29.1 \%$ during their stay at the intensive care unit, $40.2 \%$ at hospital discharge and $53 \%$ during the 30-day follow-up, which confirms the severity of their condition, which is comparable to international reports of immunocompromised patients with sepsis. Our patients with bacteremia have a $21.4 \%$ increase in absolute risk of mortality in comparison with patients with negative blood cultures.

The causes of PCT high levels with no infection present include: multiple trauma, major surgery, cardiogenic shock and the presence of metastases or carcinoma with a neuroendocrine component, which should be regarded as limitations of this biomarker ${ }^{14,18}$.

There are identified germs that stimulate higher levels of PCT, as for example E. coli, Proteus spp, and there are also differences according to the infectious focus ${ }^{15,28,29}$. In our study, the reduced number of cases of fungal infection does not allow us issuing conclusions regarding PCT and these microbial agents.

The use of PCT as a biomarker, widely available and low-cost, could increase the safety of microbiological diagnosis in sepsis, which is a desired goal in order to improve the outcomes of critically ill patients in general, and even more so in critically ill immunocompromised patients, such as those with febrile neutropenia, in whom clinical judgement added to a correct empirical antibiotic therapy will be key to sepsis control. The path of prospective research in this line is viable and necessary.

\section{Conclusions}

In critically ill patients with febrile neutropenia, a PCT cutoff value higher than $15.5 \mathrm{ng} / \mathrm{mL}$ is a predictor of bacteremia (AUC: 0.76), whereas values higher than 
$26.8 \mathrm{ng} / \mathrm{mL}$ predict gram-negative bacilli bacteremia (AUC: 0.81), which are results that may help diagnosis and therapeutic decision-making.

\section{References}

1. Stosor V, Zembower T. Infectious complications in cancer patients Neutropenic fever and sepsis: Evaluation and management. EE.UU.: Springer International Publishing; 2014.

2. Schnell D, Azoulay E, Benoit D, Clouzeau B, Demaret P, Ducassou S, et al. Management of neutropenic patients in the intensive care unit (NEWBORNS EXCLUDED) recommendations from an expert panel from the French Intensive Care Society (SRLF) with the French Group for Pediatric Intensive Care Emergencies (GFRUP), the French Society of Anesthesia and Intensive Care (SFAR), the French Society of Hematology (SFH), the French Society for Hospital Hygiene (SF2H), and the French Infectious Diseases Society (SPILF). Ann Intensive Care. 2016;6(1):90.

3. Singer M, Deutschman CS, Seymour CW, Shankar-Hari M, Annane D, Bauer M, et al. The Third International Consensus Definitions for Sepsis and Septic Shock (Sepsis-3). JAMA. 2016;315(8):801-10.

4. Lamy $B$, Dargère $S$, Arendrup MC, Parienti JJ, Tattevin P. How to optimize the use of blood cultures for the diagnosis of bloodstream infections? A state-of-the art. Front Microbiol. 2016;7:697.

5. Guo SY, Zhou Y, Hu QF, Yao J, Wang H. Procalcitonin is a marker of gram-negative bacteremia in patients with sepsis. Am J Med Sci. 2015;349(6):499-504.

6. Giamarellou H, Giamarellos-Bourboulis EJ, Repoussis P, Galani L, Anagnostopoulos N, Grecka P, et al. Potential use of procalcitonin as a diagnostic criterion in febrile neutropenia: experience from a multicentre study. Clin Microbiol Infect. 2004;10(7):628-33.

7. Diness LV, Maraldo MV, Mortensen CE, Mellemgaard A, Larsen FO. Procalcitonin and C-reactive protein as markers of bacterial infection in patients with solid tumours. Dan Med J. 2014;61(12):A4984.

8. Meidani M, Khorvash F, Abolghasemi $\mathrm{H}$, Jamali B. Procalcitonin and quantitative $\mathrm{C}$-reactive protein role in the early diagnosis of sepsis in patients with febrile neutropenia. South Asian J Cancer. 2013;2:216-9.

9. Wacker C, Prkno A, Brunkhorst FM, Schlattmann P. Procalcitonin as a diagnostic marker for sepsis: a systematic review and meta-analysis. Lancet Infect Dis. 2013;13(5):426-35.

10. Brodská $H$, Malíčková $K$, Adámková V, Benáková $H$, Št'astná MM, Zima T. Significantly higher procalcitonin levels could differentiate Gram-negative sepsis from Gram-positive and fungal sepsis. Clin Exp Med. 2013;13(3):165-70.

11. Brodská-Rüddel DO, Poidinger B, Kott M, Weiss M, Reinhart K, Bloos F. Influence of pathogen and focus of infection on procalcitonin values in sepsis patients with bacteremia or candidemia. Crit Care. 2018;22(1):128.

12. Leli C, Ferranti M, Moretti A, Al Dhahab ZS, Cenci E, Mencacci A. Procalcitonin levels in gram-positive, gram-negative, and fungal bloodstream infections. Dis Markers. 2015:701480.
13. Henriquez-Camacho C, Losa J. Biomarkers for sepsis. Biomed Res Int 2014:547818.

14. Oussalah A, Ferrand J, et al. Diagnostic accuracy of procalcitonin for predicting blood culture results in patients with suspected bloodstream infection: An observational study of 35,343 consecutive patients. Medicine (Baltimore). 2015;94(44):e1774.

15. Thomas-Rüddel DO, Poidinger $B$, Kott M, Weiss $M$, Reinhart K, Bloos F Influence of pathogen and focus of infection on procalcitonin values in sepsis patients with bacteremia or candidemia. Crit Care. 2018;22(1):128.

16. Ahn S, Lee YS, Lim KS, Lee JL. Adding procalcitonin to the MASCC risk-index score could improve risk stratification of patients with febrile neutropenia. Support Care Cancer. 2013;21(8):2303-8.

17. Wang $H$, Yin F, et al (2013). Predictive value of procalcitonin for excluding bloodstream infection: results of a retrospective study and utility of a rapid, quantitative test for procalcitonin. J Int Med Res. Oct;41(5):1671-81. doi: 10.1177/0300060513497558.

18. Liu HH, Zhang MW, Guo JB, Li J, Su L. Procalcitonin and C-reactive protein in early diagnosis of sepsis caused by either Gram-negative or Gram-positive bacteria. Ir J Med Sci. 2017;186(1):207-12.

19. Durnaś B, Wątek M, Wollny T, Niemirowicz K, Marzec M, Bucki R, Góźdź S. Utility of blood procalcitonin concentration in the management of cancer patients with infections. Onco Targets Ther. 2016;9:469-75.

20. Hoeboer SH, van der Geest PJ, Nieboer D, Groeneveld AB. The diagnostic accuracy of procalcitonin for bacteraemia: a systematic review and meta-analysis. Clin Microbiol Infect. 2015;21(5):474-81.

21. Sbrana A, Torchio M, Comolli G, Antonuzzo A, Danova M. Use of procalcitonin in clinical oncology: a literature review. New Microbiol. 2016;39(3):174-80.

22. Sakr $Y$, Sponholz C, Tuche F, Brunkhorst F, Reinhart K. The role of procalcitonin in febrile neutropenic patients: review of the literature. Infection. 2008;36(5):396-407.

23. Pan YP, Fang YP, Xu YH. The diagnostic value of procalcitonin versus other biomarkers in prediction of bloodstream infection. Clin Lab. 2017; 63(2):277-85.

24. Uys A, Rapoport BL, Fickl H, Meyer PW, Anderson R. Prediction of outcome in cancer patients with febrile neutropenia: comparison of the Multinational Association of Supportive Care in Cancer risk-index score with procalcitonin, C-reactive protein, serum amyloid $A$, and interleukins-1beta, -6, -8 and -10. Eur J Cancer Care (Engl). 2007:16(6):475-83.

25. Carnino L, Betteto S, Loiacono M, Chiappella A, Giacobino A, Ciuffreda L, Lista P, Mengozzi G. Procalcitonin as a predictive marker of infections in chemoinduced neutropenia. J Cancer Res Clin Oncol. 2010;136(4):611-5.

26. Hambach L, Eder M, Dammann E, et al. Diagnostic value of procalcitonin serum levels in comparison with C-reactive protein in allogeneic stem cell transplantation. Haematologica. 2002;87(6):643-51.

27. Giacobbe DR, Mikulska M, et al. Combined use of serum (1,3)- $\beta-D-g l u-$ can and procalcitonin for the early differential diagnosis between candidaemia and bacteraemia in intensive care units. Crit Care. 2017;21(1):176.

28. Duan J, Xie Y, Yang J, Luo Y, Guo Y, Wang C. Variation of circulating inflammatory mediators in Staphylococcus aureus and Escherichia coli bloodstream infection. Med Sci Monit. 2016;22:161-71.

29. Chaftari AM, Hachem R, et al. Role of Procalcitonin and interleukin- 6 in predicting cancer, and its progression independent of infection. PLoS One. 2015;10(7):e0130999. 